Received Date : 22-Jul-2016

Revised Date : 30-Aug-2016

Accepted Date : 30-Aug-2016

Article type $\quad$ : B - Brief Communication

\title{
Optimising Outcomes in Pediatric Renal Transplantation through the Australian Paired Kidney Exchange Program
}

Sypek MP ${ }^{1,2,3}$, Alexander $\mathrm{SI}^{4}$, Cantwell $\mathrm{L}^{5}$, lerino $\mathrm{FL}^{1,3,6}$, Ferrari $\mathrm{P}^{7}$, Walker $\mathrm{AM}^{1,3,8}$, Kausman $J Y^{1,2,3,8}$

Affiliations

${ }^{1}$ Royal Children's Hospital, Victoria, Australia

${ }^{2}$ Royal Melbourne Hospital, Victoria, Australia

${ }^{3}$ University of Melbourne, Victoria, Australia

${ }^{4}$ Children's Hospital at Westmead \& The University of Sydney, NSW, Australia

${ }^{5}$ Victorian Transplantation and Immunogenetics Service, Victoria, Australia

${ }^{6}$ Austin Health, Victoria, Australia

${ }^{7}$ Prince of Wales Hospital \& The University of New South Wales, NSW, Australia

${ }^{8}$ Murdoch Children's Research Institute, Victoria, Australia

Corresponding author:

Dr Matthew Sypek

Department of Nephrology

Royal Children's Hospital

50 Flemington $\mathrm{Rd}$,

This is the author manuscript accepted for publication and has undergone full peer review but has not been through the copyediting, typesetting, pagination and proofreading process, which may lead to differences between this version and the Version of Record. Please cite this article as doi: $\underline{10.1111 / a j t .14041}$

This article is protected by copyright. All rights reserved 
Parkville, Victoria, Australia, 3052.

Email: matthew.sypek@rch.org.au

Running Title: Pediatric Kidney Paired Donation

\section{Abbreviations}

AKX, Australian Kidney Exchange

ARPKD, autosomal recessive polycystic kidney disease

CAKUT, congenital abnormalities of the kidney and urinary tract

CDC, complement dependent cytotoxicity

CPRA, calculated panel reactive antibody

DSA, donor specific antibody

ESKD, end stage kidney disease

FCXM, flow cytometric crossmatch

HBcAb, hepatitis B core antibody

HBsAb, hepatitis B surface antibody

$\mathrm{HBsAg}$, hepatitis B surface antigen

HLA, human leukocyte antigen

LDKT, living donor kidney transplantation

KPD, kidney paired donation

$\mathrm{MFI}$, mean fluorescence intensity

PUV, posterior urethral valves

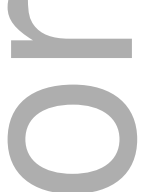

\section{Abstract}

Kidney paired donation (KPD) programs offer the opportunity to enable living kidney donation when immunological and other barriers prevent safe directed donation. Children are likely to require multiple transplants during their lifetime, therefore, high level histocompatibility and organ quality matching are key priorities. A cohort of seven pediatric renal transplants performed through the Australian Kidney Exchange (AKX) is outlined including barriers to alternative transplant and outcomes after KPD. Reasons for entering KPD were pre-formed donor specific antibodies (DSA) to their registered donor in five cases, ABO mismatch, and avoidance of the risk of exposure to hepatitis B virus. Four recipients were highly sensitized. All This article is protected by copyright. All rights reserved 
patients received transplants with organs of lower immunological risk compared with their registered donors. HLA eplet mismatch scores were calculated for donor recipient pairs; three patients had improved eplet mismatch load with AKX donor compared to registered donor. All grafts are functioning, mean eGFR $77 \mathrm{ml} / \mathrm{min} / 1.73 \mathrm{~m}^{2}$ (range $46-94 \mathrm{ml}$ ), with a follow up range 854 months and no patient has experienced any episodes of clinical or histological rejection. KPD is a viable strategy to overcome many barriers to living donation for pediatric patients who have an otherwise suitable donor and provides an opportunity to minimise immunological risks.

\section{Introduction}

Renal transplantation is the optimal treatment for children with end stage kidney disease (ESKD) conferring a survival advantage compared with remaining on dialysis (1), improving linear growth (2), and providing improved quality of life and opportunities for education and development. There are approximately 35-50 pediatric renal transplants performed in Australia annually and living donor kidney transplantation (LDKT), predominantly from a family member, accounts for over half of these (3). However, in a number of cases there may be immunological barriers to transplantation from potential living donors including pre-existing donor specific antibodies (DSA), or blood group mismatch that can prevent direct donation.

There have been two strategies to deal with pre-existing immune barriers to transplantation. The first, pioneered in the US and Japan, has been the development of stronger immune suppression to allow transplantation across pre-existing anti-HLA or anti-ABO antibodies. This has involved plasma exchange, B cell depletion and even splenectomy and currently is successfully used for $A B O$ mismatched transplants and transplantation of highly sensitized recipients (4-6). The second has been the identification of a lower risk donor and prioritizing this for the recipient. In kidney paired donation (KPD) programs this allows access to better HLA or blood group matched living donors and in the Eurotransplant acceptable mismatch program, highly sensitized patients are given priority for organs from deceased donors with HLA alleles that are at low risk of producing a positive cross match (7). While both desensitization and ABO mismatched transplants have been successfully performed for children $(4,8)$, KPD offers access to LDKT without the associated higher immunosuppression required to overcome these immune barriers.

This article is protected by copyright. All rights reserved 
The Australian Kidney Exchange (AKX) was established in 2010 as an initiative of the national Organ and Tissue Authority, which also covers the retrieval and use of deceased donors. The program is federally funded and there is no direct cost to individuals or transplant centres to participate. The AKX is the only KPD program in Australia. It has enabled over 170 living donor kidney transplants and in 2015 KPD transplants accounted for 19\% of all living donor transplants(9). The primary reason for pairs participating in the AKX is HLA incompatibility. An additional $14 \%$ register due to $A B O$ blood group mismatch. Match runs are conducted every 3 months, with an average of 45-55 participant pairs, including 10-20 new pairs per run accrued between each match cycles. Due to the small pool size, more frequent matching cycles would be ineffective, as a sufficiently large number of new donors is necessary to optimize match probability. The cumulative match efficiency of the program is $82 \%$, however, due to post matching clinical issues, only $52 \%$ of registered participants have undergone transplantation through the program. The median time from registration to transplant is 173 days (95\% Cl 59738), but for patient with cPRA 95-100\% this increases to 229 days (95\% Cl 64-1179). We have previously shown this compares favourably to the waiting time for a deceased donor kidney(10), which in the highly sensitized category (PRA $>80 \%$ ) is on average 5.1 years(11). The AKX allows for $A B O$ mismatched donors to be offered to consented recipients with low blood group specific antibody titre, and allows for Hepatitis B core antibody (HepBcAb) positive donor organs to be offered to consented recipients with evidence of immunity to Hepatitis $B$.

Most pediatric renal transplant candidates will require multiple transplants throughout their lifetime and hence strategies to optimize immunological matching with the aim of prolonging graft survival and minimizing anti-HLA sensitization to potential future donors are of paramount importance in this population. The burden of HLA mismatching is increasingly recognized both by HLA typing and by more sophisticated epitope based measures of immunogenicity (12-14). The AKX calculates eplet mismatch scores and provides this information to clinicians to aid in the decision-making. However, when deciding on whether to proceed with a specific transplant, immunological priorities must be viewed in the context of recipient stability and urgency of transplantation, the likelihood of access to transplantation from other sources, such as the deceased donor list and the organ quality.

\section{Materials and Methods}

This article is protected by copyright. All rights reserved 
This is a cohort of pediatric kidney transplants performed through the AKX in Australia. Cases were identified by searching the AKX database for kidney recipients $<18$ years of age at the time of transplant. Clinical data were obtained from local hospital case histories. Local ethics guidelines concerning the publication of case series were followed. Extended HLA typing to a four-digit level at HLA A*, B*, C*, DRB1*, DQB1*, and DPB1*, and to a 2 digit level at DQA1* and $\mathrm{DRB}^{*} 3 / 4 / 5$ is required for all registered donors and recipients in AKX. Mismatches are reported based on high resolution allele typing when available or serological equivalents for historical transplants. Eplet analysis was generated using ABC + DRDQDP Eplet Matching Macro v2.1: (available at: www.epitopes.net). Anti-HLA antibodies were tested using Luminex Single Antigen Bead kits (OneLamda, Canoga Park, CA), and considered positive for Mean Fluorescence Intensity (MFI) >1000. Estimated glomerular filtration rate (eGFR) was calculated using the revised Schwartz formula (15). Post-transplant protocol biopsies were not routinely performed in this cohort, except for case 2 who received an ABO mismatched transplant. Posttransplant monitoring for DSAs was performed at the discretion of treating clinicians.

\section{Results}

Seven pediatric kidney transplants performed through the AKX are described (the details of one additional case, transplanted at another centre, were not available to the authors for this report). Table 1 summarizes the demographics and baseline characteristics. Table 2 reports the immunological details between each recipient and both their registered donor and matched AKX donor, from whom they subsequently received an organ. Table 3 shows the outcomes of transplants performed through the AKX. The details of case 2 have been previously published (16).

The children ranged in age from 3 to 17 years with a mean age of 10 years at time of transplantation. There were four boys and three girls. In five children this was their first transplant and in two it was a retransplant. The etiology of renal failure included: five children with posterior urethral values (PUV), dysplasia or congenital abnormalities of the kidney and urinary tract (CAKUT); one child with autosomal recessive polycystic kidney disease (ARPKD) and one with congenital nephrotic syndrome. Six children were sensitized to HLA antigens, 2 as a result of previous transplantation and 4 from previous transfusion. Four were highly sensitized with calculated panel reactive antibody (cPRA) $>80 \%$. Of the six sensitized patients, 5 had DSA to their registered donor (MFI range 1,796 - >20,000), which was their reason for This article is protected by copyright. All rights reserved 
entering the AKX. One patient (case 7) entered due to ABO mismatch with his registered donor (group $A \rightarrow$ group 0, anti-A titre 1:32). One case (case 6) was a 3 year-old girl whose registered donor was HepBcAb positive. Six of the seven cases were on dialysis at the time of transplantation.

AKX match cycles occur every 3 months and three children were matched on the first run, three were matched within 4 runs, and one highly sensitized boy with a CPRA $99.8 \%$ was in the KPD program for 13 match cycles. All recipients had negative complement dependent cytotoxicity (CDC) crossmatches with their AKX donors prior to transplantation. Flow cytometric crossmatches (FCXM) were performed in selected cases (table 2). All patients received transplants with lower immunological risk compared to their registered donor, however, for the 4 highly sensitized patients, compromises on aspects of immunological matching were made due to low likelihood of receiving an organ from another source and/or the clinically urgent need for transplantation. These risks included: $A B O$ mismatch (case 2), repeat HLA mismatch with previous transplant (case 3), DSA (cases 2,4 and 5) and high eplet loads (cases 3 and 5). Case 2 was matched to an $A B O$ mismatched donor (donor group B, recipient group $O$, anti-B titre 1:8 against donor cells) to whom he had a number of historical DSA in his $13^{\text {th }}$ AKX run. Both anti-B titres and DSA MFIs were low on his most recent serum samples and there was a negative CDC and flow cytometric crossmatch on current serum. He was successfully transplanted using a desensitization regimen(16). In case 5, the AKX donor, although of suboptimal HLA matching, overcame the presence of a high level DSA and positive CDC B cell crossmatch with the registered donor and fulfilled an urgent need to imminent transplantation. Eplet mismatches in the entire cohort ranged from 13-116 between the children and their AKK donor. Three patients had lower eplet mismatches with their AKX compared to their registered donor.

All patients in this case series received standard immunosuppression, comprising induction with basiliximab and methylprednisolone followed by maintenance with tacrolimus, mycophenolate and prednisolone. The desensitization protocol for case 2 has been previously reported (15) and case 4 received two 1.5 plasma volume exchanges pre transplant.

Australia is a land of great distance and a national program requires the capacity to fly kidneys around the country. In this program one pair of kidneys travelled 3,938 km between Perth and Sydney. However, there were no reports of delayed graft function in any recipients. Clinical This article is protected by copyright. All rights reserved 
outcomes have been good; no patient experienced any episodes of clinical or histological rejection and there has been no graft or patient loss. Two patients had been treated for mild CMV viraemia with effective clearance. All grafts are functioning, mean eGFR $77 \mathrm{ml} / \mathrm{min} / 1.73 \mathrm{~m}^{2}$ (range 46-94), with a follow up range from 8-54 months. This compares to 1 and 5 year graft survival of $97 \%$ and $84 \%$ respectively in the general pediatric transplant population (3). There is one patient with an eGFR $<60 \mathrm{ml} / \mathrm{min} / 1.73 \mathrm{~m}^{2}$ on follow up. Patient 2 had donor arteriopathy noted at implantation biopsy, which was a persistent finding on surveillance biopsies, however, there was no histopathological evidence of rejection. Biopsy at 24 months showed interstitial fibrosis and tubular atrophy with intimal fibroelastic hyperplasia of small arteries but no transplant glomerulopathy or C4d deposition. MFIs of his pre transplant DSAs had reduced at 12 and 18 months post-transplant (table 3). Overall, post-transplant monitoring for DSA was performed in six of the seven patients (table 3). Case 1 was noted to have a low level de novo DSA (CW4 (MFI 1,438) at 12 month screening; her graft function was stable, she was not biopsied and DSA will continue to be monitored annually.

\section{Discussion}

With modern immunosuppressive regimens, transplantation across a number of immunological barriers has become possible, including HLA incompatibility and ABO mismatch (5)(17). However, management of children with ESKD should balance the short-term goal of access to transplantation with life-long goals of optimal graft survival, minimizing sensitization and maintenance of future re-transplantation opportunities; while minimizing immunosuppressionassociated morbidity in the context of a developing immune system and the long-term risks of opportunistic infection and malignancy. It is in this context that targets of immunological matching are often set at higher levels for children compared to older adults, for whom timely access to organs in the context of life limiting comorbidities may be of greater importance. The detailed donor information in KPD programs provide an opportunity for a sophisticated immunological comparative assessment of the registered and matched donors, while also facilitating the benefits of LDKT(18).

In this cohort, reducing the risks of preformed HLA or ABO blood group antibodies and avoiding the potential exposure to a blood borne virus have been the motivations for participation in KPD. The presence of pre-transplant DSA has been associated with poor outcomes including increased rates of antibody-mediated rejection and reduced graft survival even in the presence This article is protected by copyright. All rights reserved 
of a negative crossmatch at the time of transplantation (19). In case 1 , matching through the AKX allowed the recipient to avoid a DSA with MFI 4,744, and receive a transplant of much lower immunological risk with no DSA and excellent eplet matching.

The challenges in finding compatible donors for highly sensitized patients, either living or within the deceased donor pool, are significant (20)(21). The current Australian deceased donor organ allocation gives priority to highly sensitized patients (cPRA $>80 \%$ ) with fewer than three HLA antigen mismatches. Despite this, the mean waiting time for highly sensitized patients (adult and pediatric) is 5.1 years(11). There is no targeted bonus system for the very highly sensitized analogous to the recently introduced US Kidney Allocation System (KAS). The AKX provides an avenue to both retain the benefits of a LDKT and facilitate timely access to transplantation. Since its inception, 35\% of patients registered in the AKX have had a cPRA >95\% (9). Four (57\%) of the children in this series were highly sensitized from previous transplantation or transfusion, with CPRA $>80 \%$ and all had DSA to their prospective donors. All of these patients received organs with lower risk profile compared to their registered donor, however, due to the limited access to suitable donors for these 4 patients, their interests were felt to be best served by accepting some compromises on immunological risks, balanced by the benefits of a planned LDKT. This point is demonstrated in case 2 who had no deceased donor offers for more than 3 years but was able to be transplanted through PKD with an ABO mismatched organ to which he had a number of historical DSA.

Repeat HLA mismatches have historically been associated with poorer long term outcomes (22) and many deceased donor organ allocation algorithms exclude offers in the context of repeat mismatches. The ability to determine allele specific antibodies has led some to challenge this position (23). One patient (case 3) had no pre-formed antibodies to the three antigens that were a repeat mismatch with her previous donor, despite demonstrated ability to form other anti-HLA antibodies, possibly suggesting tolerance to these alloantigens. The low number of foreign epitopes on these antigens provides a plausible explanation for absence of an antibody response and offered reassurance in proceeding with this transplant in the face of repeat mismatches.

KPD can provide effective access to transplantation in the setting of urgent clinical need when an available living donor is high risk for direct donation. Case 5 had complications of hemodialysis in his first 3 months of therapy and was unlikely to receive an imminent offer This article is protected by copyright. All rights reserved 
through the deceased donor program due to his broad sensitization, particularly as he had not yet qualified for pediatric bonus points in the Australian deceased donor organ allocation (awarded to patients $<18$ years of age who have been on dialysis treatment for greater than 12 months). The AKX met the urgent clinical need with a calculated compromise on immunological matching in order to achieve the medical and psychosocial benefits of transplantation.

Epitope analysis can provide a structurally based approach to HLA compatibility and may be superior at predicting clinical outcomes when compared to conventional HLA antigen level analysis; including DSA formation (14)(13) and risk of sensitization (13). One patient (case 4) was a haplotype match with his potential donor with relatively low eplet mismatch scores (class I 13, class II 18) but a weak DSA (MFI 1,795) and positive B cell FCXM. Although low level, the DSA against his registered donor was part of the A2-B57 cross reactive group (CREG) with 5 different allele beads being positive on Luminex anti-HLA antibody testing. Enhanced sensitization to this shared epitope through exposure to an HLA B57 positive organ may have produced significant limitations on the range of future potential donors. Despite the presence of 2 low-level DSA against the matched donor, other advantages included a lower age discrepancy between donor and recipient, and a lower class II eplet mismatch favored this donor. In-depth analysis of eplet based matching requires high resolution HLA extended typing, which is not routinely performed in many transplant immunology laboratories, and considerable time and expertise for analysis. While this is available in the AKX, further clinical studies are required to validate the theoretical advantages of this novel approach to HLA matching.

While $A B O$ mismatched kidney transplantation in children has been shown to be highly successful with outcomes in small cohorts equivalent to $A B O$ compatible pairs (4)(24), the requirement of additional immunosuppressive therapy may increase the risk of long term infective and malignant complications (25)(26). One patient (case 7) was able to receive an ABO matched transplant after two runs in the AKX. Both ABO mismatched transplantation and KPD can enable living donor transplantation for children with ESKD and the risks and benefits of each option should be assessed in individual cases. KPD may be superior in cases of high anti$A B O$ antibody titres or in very young children, where the risks of central venous access and hemodynamic shifts associated with plasma exchange present additional challenges for ABO mismatched transplants.

This article is protected by copyright. All rights reserved 
Finally, the AKX allows additional risk-profiling, which can be particularly beneficial for children, for whom long-term consequences need to be carefully considered. HBcAb positivity is a marker of prior exposure to the hepatitis B virus, and while HBsAg negative, HBsAb positive status is indicative of immunity following prior exposure, there remains a theoretical possibility of transmission of latent infection through solid organ transplantation. Studies of adult kidney transplant recipients receiving $\mathrm{HBcAb}$ positive, $\mathrm{HBsAg}$ negative organs, have indicated that although a small number of patients will seroconvert to HBcAb positive post-transplant, the risk of developing active hepatitis B is extremely low (27) and the long-term graft and patient survival rates are comparable to hepatitis B negative donors (28). HBcAb positive donors are offered to appropriately immunized adult recipients with specific informed consent, however, the lack of long-term infection and malignancy outcome data in children has led to recommendations for caution in accepting these donors for children (29)(30). Through the AKX, one patient (case 6) whose intended donor was HBCAb positive, received an organ without the identified risk of viral transmission, which in addition provided excellent immunological matching and a smaller age discrepancy than with her registered donor.

We report seven pediatric renal transplants performed through the AKX since its introduction in 2010. Six of these transplants were performed at one centre, which accounts for $<25 \%$ of Australian pediatric renal transplants. However, there has been increasing uptake in Australia with an additional eight patients now listed from four of the seven pediatric transplanting units, facilitated by free access to the program, clear guidelines for entry requirements and dedicated coordinators to facilitate surgical dates and logistics. Additional barriers for pediatric, compared to adult candidates in KPD programs include organ size matching and anatomical considerations, the exclusion of HepBcAb positive donors for many recipients and the ethical concerns of accepting young parent donors whose long term outcomes are less certain and who may wish to have additional children in the future. We have also found that many related donors feel a strong emotional desire to donate directly to their child, which must be addressed sensitively and in the context of the potential benefits of PKD. It has been shown that by increasing the total number of pairs in a KPD program the match probability is improved for all participants, including the highly sensitized patients, providing an overall benefit to the system $(31,32)$.

In summary, our cohort demonstrates that KPD is an effective strategy to overcome many of the barriers to LKDT for pediatric patients who have an otherwise suitable donor, including This article is protected by copyright. All rights reserved 
those who are ABO mismatched or HLA-incompatible, or have an increased risk of transmitting a chronic infection. The immunologically well-characterized and large live donor pool in a KPD program provides an opportunity to minimize donor-recipient HLA epitope mismatches. However, it remains unclear whether improved epitope matching will reduce the risk of de novo HLA antibodies, and contribute to improved graft outcomes and reduced rates of sensitization

\section{Acknowledgments}

We would like to acknowledge the RCH transplant coordinator: Ms Esther Macknamara; RCH surgical team: Mr lan Michell, Prof David Francis, Mr Mike O’Brien and Prof Yves Heloury; colleague: Dr Cathy Quinlan and CHW surgeons Dr Albert Shun and Dr Gordon Thomas.

\section{Disclosure}

The authors of this manuscript have no conflicts of interest to disclose as described by the American Journal of Transplantation.

\section{References}

1. McDonald SP, Craig JC. Long-Term Survival of Children with End-Stage Renal Disease. N Engl J Med. 2004;350(26):2654-62.

2. Pape L, Ehrich JHH, Zivicnjak M, Offner G. Growth in children after kidney transplantation with living related donor graft or cadaveric graft. Lancet. 2005;366(9480):151-3.

3. ANZDATA Annual Report: Chapter 11 Paediatrics. http://www.anzdata.org.au/v1/report_2014.html. 2014;

4. Tydén G, Kumlien G, Berg UB. ABO-incompatible kidney transplantation in children. Pediatr Transplant. 2011;15(5):502-4.

5. Al Meshari K, Pall A, Chaballout A, El Gamal H, Al Mana H, Humaidan H, et al. Outcome of desensitization in human leukocyte antigen- and ABO-incompatible living donor kidney transplantation: A single-center experience in more than 100 patients. Transplant Proc. Elsevier Inc.; 2013;45(4):1423-6.

This article is protected by copyright. All rights reserved 
6. Montgomery RA, Lonze BE, King KE, Kraus ES, Kucirka LM, Locke JE, et al. Desensitization in HLA-Incompatible Kidney Recipients and Survival. N Engl J Med. 2011;365(4):318-26.

7. Heidt S, Witvliet MD, Haasnoot GW, Claas FHJ. The 25th anniversary of the Eurotransplant Acceptable Mismatch program for highly sensitized patients. Transpl Immunol. Elsevier B.V.; 2015;33(2):51-7.

8. Pirojsakul K, Desai D, Lacelle C, Seikaly MG. Management of sensitized pediatric patients prior to renal transplantation. Pediatr Nephrol. 2016; epub.

9. Australian Paired Kidney Exchange Programme Biannual Report \#6.

http://www.donatelife.gov.au/about-us/kidney-exchange-programme. 2015;

10. Ferrari P, Fidler S, Woodroffe C, Tassone G, D'Orsogna L. Comparison of time on the deceased donor kidney waitlist versus time on the kidney paired donation registry in the Australian program. Transpl Int. 2012;25(10):1026-31.

11. Wright J NS. Analysis of Kidney Allocation During 2015 National Organ Matching System. http://www.tsanz.com.au/committees/documents/2015kidneytransplantanalysis.pdf. 2016; (May).

12. Tambur AR, Claas FHJ. HLA epitopes as viewed by antibodies: What Is it all about? Am J Transplant. 2015;15(5):1148-54.

13. Kosmoliaptsis V, Mallon DH, Chen Y, Bolton EM, Bradley AJ, Taylor CJ. Alloantibody responses after renal transplant failure can be better predicted by donor-recipient HLA amino acid sequence and physicochemical disparities than conventional HLA matching. Am J Transplant. 2016;16:2139-47.

14. Wiebe C, Pochinco D, Blydt-Hansen TD, Ho J, Birk PE, Karpinski M, et al. Class II HLA epitope matching - A strategy to minimize de novo donor-specific antibody development and improve outcomes. Am J Transplant. 2013;13(12):3114-22.

15. Schwartz GJ, Muñoz A, Schneider MF, Mak RH, Kaskel F, Warady BA FS. New Equations to Estimate GFR in Children with CKD. J Am Soc Nephrol. 2009;20:629-37.

16. Carter SA, Kausman JY. ABO-incompatible, paired kidney exchange transplantation in a highly sensitized patient with donor-specific antibodies. Pediatr Nephrol. 2015;30(9):1541-2.

17. Riella L V, Safa K, Yagan J, Lee B, Azzi J, Najafian N, et al. Long-Term Outcomes of Kidney Transplantation Across a Positive Complement-Dependent Cytotoxicity Crossmatch. Transplantation. 2014;97(12):1247-52.

18. Nayak AB, Ettenger RB, McGuire S, Lipshutz GS, Reed EF, Veale J, et al. Optimizing HLA matching in a highly sensitized pediatric patient using ABO-incompatible and paired This article is protected by copyright. All rights reserved 
exchange kidney transplantation. Pediatr Nephrol. 2015;30(5):855-8.

19. Lefaucheur C, Loupy A, Hill GS, Andrade J, Nochy D, Antoine C, et al. Preexisting donorspecific HLA antibodies predict outcome in kidney transplantation. J Am Soc Nephrol. 2010;21(8):1398-406.

20. Keith DS, Vranic GM. Attending Rounds Approach to the Highly Sensitized Kidney Transplant Candidate Case Presentation. Clin J Am Soc Nephrol. 2016;epub.

21. Stewart DE, Kucheryavaya AY, Klassen DK, Turgeon NA, Formica RN AM. Changes in Deceased Donor Kidney Transplantation One Year after KAS Implementation. Am J Transplant. 2016;16:1834-47.

22. Cecka JM TP. Repeating HLA Antigen Mismatches in Renal Retransplants - A second class mistake? Transplantation. 1994;57(4):515-9.

23. Tinckam KJ1, Rose C2, Hariharan S3 GJ. Re-Examining Risk of Repeated HLA Mismatch in Kidney Transplantation. J Am Soc Nephrol. 2016;

24. Mamode N, Marks SD. Maximising living donation with paediatric blood-groupincompatible renal transplantation. Pediatr Nephrol. 2013;28(7):1037-40.

25. Habicht A, Bröker V, Blume C, Lorenzen J, Schiffer M, Richter N, et al. Increase of infectious complications in ABO-incompatible kidney transplant recipients-a single centre experience. Nephrol Dial Transplant. 2011;26(12):4124-31.

26. Sharif A, Alachkar N, Bagnasco S, Geetha D, Gupta G, Womer K, et al. Incidence and outcomes of BK virus allograft nephropathy among ABO- and HLA-incompatible kidney transplant recipients. Clin J Am Soc Nephrol. 2012;7(8):1320-7.

27. Mahboobi N, Tabatabaei S V., Blum HE, Alavian SM. Renal grafts from anti-hepatitis B core-positive donors: A quantitative review of the literature. Transpl Infect Dis. 2012;14(5):445-51.

28. Ouseph R, Eng M, Ravindra K, Brock GN, Buell JF, Marvin MR. Review of the use of hepatitis B core antibody-positive kidney donors. Transplant Rev. Elsevier Inc.; 2010;24(4):167-71.

29. Ruebner RL, Moatz T, Amaral S, Reese PP, Blumberg EA, Smith JM, et al. Outcomes Among Children Who Received a Kidney Transplant in the United States From a Hepatitis B Core Antibody-Positive Donor, 1995-2010. J Pediatric Infect Dis Soc. 2015; epub.

30. Huprikar S, Danziger-Isakov L, Ahn J, Naugler S, Blumberg E, Avery RK, et al. Solid organ transplantation from hepatitis $B$ virus-positive donors: Consensus guidelines for recipient management. Am J Transplant. 2015;15(5):1162-72.

31. Ferrari P, Cantwell L, Ta J, Woodroffe C, D’Orsogna L, Holdsworth R. Providing BetterThis article is protected by copyright. All rights reserved 
Matched Donors for HLA Mismatched Compatible Pairs Through Kidney Paired Donation. Transplantation. 2016;epub.

32. Gentry SE, Segev DL, Simmerling M, Montgomery RA. Expanding kidney paired donation through participation by compatible pairs. Am J Transplant. 2007;7(10):2361-70.

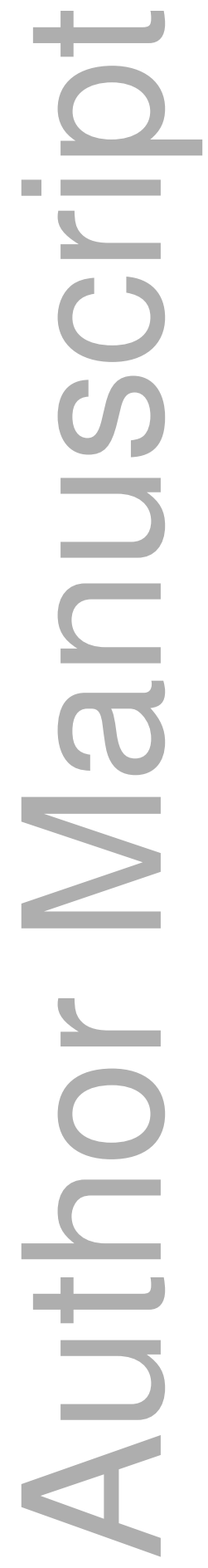

This article is protected by copyright. All rights reserved 
Table 1 Demographics and baseline characteristics of patients.

\begin{tabular}{|c|c|c|c|c|c|c|c|c|c|}
\hline Case & $\begin{array}{c}\text { Age at } \\
\text { Transplant }\end{array}$ & $\begin{array}{c}\text { Cause of } \\
\text { ESKD }\end{array}$ & $\begin{array}{l}\text { No. of } \\
\text { runs in } \\
\text { AKX }\end{array}$ & Comorbidities & $\begin{array}{c}\text { Sensitizing } \\
\text { Events }\end{array}$ & $\begin{array}{l}\text { Reason for } \\
\text { AKX }\end{array}$ & $\begin{array}{l}\text { Class I } \\
\text { CPRA }\end{array}$ & $\begin{array}{c}\text { Class II } \\
\text { CPRA }\end{array}$ & $\begin{array}{c}\text { Combined } \\
\text { CPRA }\end{array}$ \\
\hline & & & & & & & & & \\
\hline 1 & & ARPKD & 3 & $\begin{array}{c}\text { Liver disease, } \\
\text { Pulmonary } \\
\text { Hypoplasia, } \\
\text { Hypothyroidism }\end{array}$ & $\begin{array}{c}\text { Blood } \\
\text { Transfusion }\end{array}$ & DSA & $70 \%$ & $25 \%$ & $78 \%$ \\
\hline 2 & $14 y$ & PUV & 13 & $\begin{array}{c}\text { GORD with } \\
\text { fundoplication, } \\
\text { anxiety, bilateral } \\
\text { native } \\
\text { nephrectomies }\end{array}$ & Previous Tx & DSA & $99 \%$ & $94 \%$ & $99.8 \%$ \\
\hline 3 & & $\begin{array}{c}\text { Renal } \\
\text { Hypodysplasia }\end{array}$ & 1 & PCOS & Previous Tx & DSA & $56 \%$ & $86 \%$ & $92 \%$ \\
\hline 4 & $16 y$ & PUV/Dysplasia & 1 & Mitrofanoff & $\begin{array}{c}\text { Blood } \\
\text { transfusion }\end{array}$ & DSA & $86 \%$ & $0 \%$ & $86 \%$ \\
\hline 5 & & $\begin{array}{l}\text { Dysplasia/ } \\
\text { Perinatal } \\
\text { Ischaemia }\end{array}$ & 4 & $\begin{array}{l}\text { Diabetes insipidus, } \\
\text { autism spectrum } \\
\text { disorder }\end{array}$ & $\begin{array}{c}\text { Blood } \\
\text { transfusion }\end{array}$ & $\begin{array}{l}\text { DSA, need for } \\
\text { urgent } \\
\text { transplant due } \\
\text { to HDx }\end{array}$ & $86 \%$ & $68 \%$ & $96 \%$ \\
\hline
\end{tabular}

This article is protected by copyright. All rights reserved 
complications

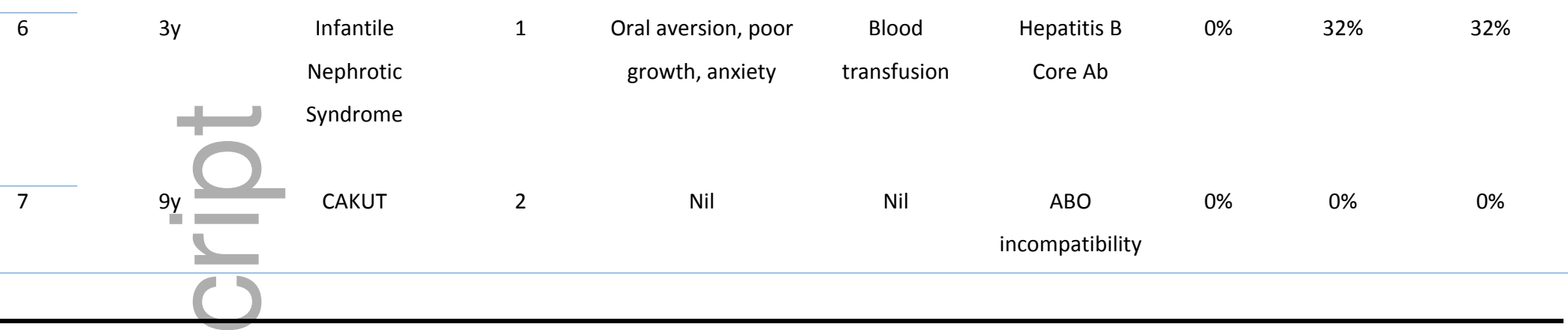

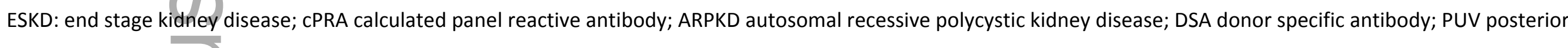

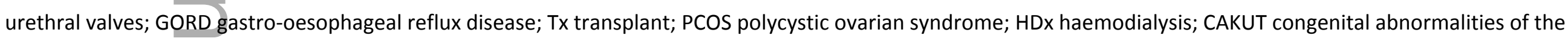
kidney and urinary tract; VUR vesicoureteric reflux disease.

Table 2. Comparison in immunological matching for each recipient $(R)$ with their registered and $A K X$ donor(D)

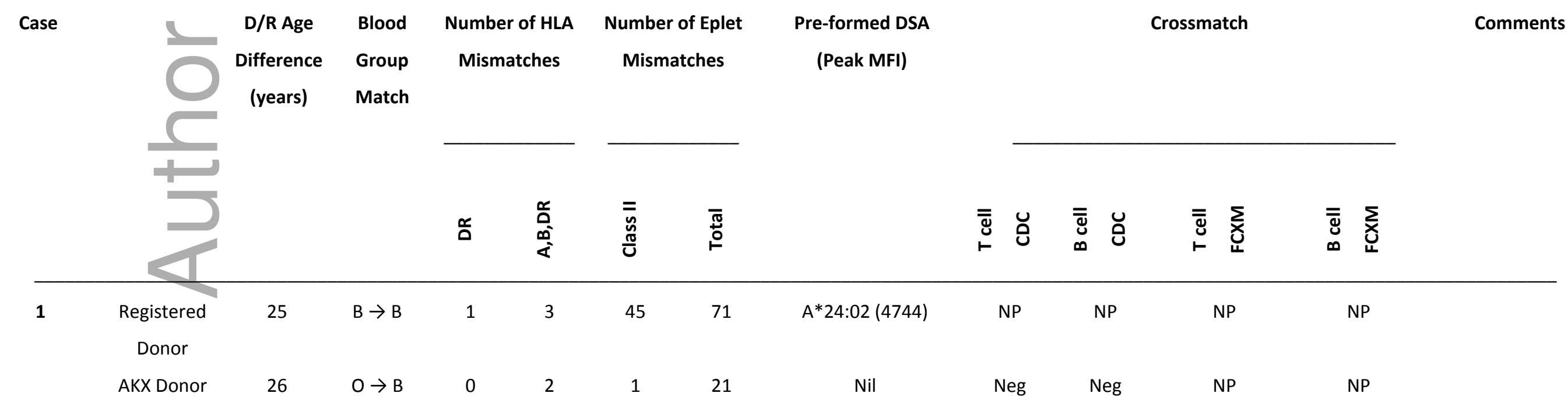

This article is protected by copyright. All rights reserved 


\begin{tabular}{|c|c|c|c|c|c|c|c|c|c|c|c|c|c|}
\hline \multirow[t]{6}{*}{2} & $\begin{array}{l}\text { Registered } \\
\text { Donor }\end{array}$ & 30 & $0 \rightarrow 0$ & 1 & 2 & 19 & 23 & $\begin{array}{l}\text { A68 \& DR13 } \\
(>20,000)^{1}\end{array}$ & $\begin{array}{l}\text { Pos } \\
\text { (Neg }\end{array}$ & $\begin{array}{l}\text { Pos } \\
\text { (Neg }\end{array}$ & Pos & Pos & $\begin{array}{c}{ }^{1} \text { Repeat HLA MM } \\
\text { with prev Tx }\end{array}$ \\
\hline & ת & & & & & & & & DTT) & DTT) & & & \\
\hline & AKX Donor & 47 & $\mathrm{~B} \rightarrow \mathrm{O}$ & 1 & 4 & 30 & 37 & & Neg & Neg & Pos (peak) & Pos (peak) & ${ }^{2}$ All $<1000$ pre-Tx. \\
\hline & & & & & & & & $(11,111) ; \mathrm{B} 62$ & & & Neg (current) & Neg (current) & \\
\hline & & & & & & & & $(18,757)$ \& DR7 & & & & & \\
\hline & & & & & & & & $(4,244)^{2}$ & & & & & \\
\hline \multirow[t]{7}{*}{3} & Registe & 33 & $A \rightarrow A$ & 1 & 2 & 27 & 42 & DQB1*03:01, & $\mathrm{Neg}$ & Pos & NP & NP & \\
\hline & Done & & & & & & & $\mathrm{DQA}^{*} 01 \mathrm{MFI}(>8,000)$ & & & & & \\
\hline & AKX Dor & 28 & $\mathrm{O} \rightarrow \mathrm{A}$ & 2 & 5 & 43 & 70 & Nil & Neg & Neg & Neg & Neg & Repeat HLA MM \\
\hline & & & & & & & & & & & & & with prev $T x$ \\
\hline & & & & & & & & & & & & & (DRB1*15:01, \\
\hline & & & & & & & & & & & & & DPB1*04:01 \\
\hline & & & & & & & & & & & & & DRB4*01:01) \\
\hline \multirow[t]{5}{*}{4} & Regist & 26 & $A \rightarrow A$ & 1 & 3 & 18 & 31 & $B * 57: 01$ (1796) & Neg & Pos & Neg & Pos & \\
\hline & & & & & & & & & & (Neg & & & \\
\hline & & & & & & & & & & DTT) & & & \\
\hline & AKX Donor & 16 & $A \rightarrow A$ & 1 & 4 & 12 & 28 & A*32:01 (1344), B27 & Neg & Neg & NP & NP & ${ }^{3}$ No allele specific \\
\hline & & & & & & & & $(1279)^{3}$ & & & & & bead for $B * 27: 02$ \\
\hline \multirow[t]{3}{*}{5} & Registered & 36 & $A \rightarrow A$ & 1 & 3 & 3 & 17 & A*24:02 (8119); & Neg & Pos & NP & NP & \\
\hline & Donor & & & & & & & DPB1*04:02 (1257) & & & & & \\
\hline & AKX Donor & 31 & $A \rightarrow A$ & 2 & 5 & 86 & 116 & $\mathrm{~B}^{*} 07: 02$ (1038) & Neg & Neg & NP & NP & \\
\hline
\end{tabular}

This article is protected by copyright. All rights reserved 


\begin{tabular}{|c|c|c|c|c|c|c|c|c|c|c|c|c|}
\hline \multirow[t]{3}{*}{6} & Registered & 56 & $A \rightarrow A$ & 0 & 1 & 0 & 21 & Nil & NP & NP & NP & NP \\
\hline & Donor & & & & & & & & & & & \\
\hline & AKX Donor & 46 & $\mathrm{O} \rightarrow \mathrm{A}$ & 1 & 4 & 0 & 13 & Nil & Neg & Neg & NP & NP \\
\hline \multirow[t]{2}{*}{7} & $\begin{array}{c}\text { Registered } \\
\text { Donor }\end{array}$ & 34 & $A \rightarrow O$ & 1 & 3 & 14 & 23 & $\mathrm{Nil}$ & NP & NP & NP & NP \\
\hline & AKX Donor & 37 & $0 \rightarrow 0$ & 2 & 6 & 17 & 36 & DRB1*03:02 $(<1000)^{\#}$ & Neg & NP & NP & NP \\
\hline
\end{tabular}

Traditional HLA matching includes HLA A,B and DRB1, with up to six potential mismatches. Eplet matching shows the number of eplet mismatches calculated using HLAMatchmaker based on HLA-A/B/C/DRB1/3/4/5/DQB1/DQA1/DPB1.

Donor-specific antibodies (DSA) are shown with peak serum mean fluorescence intensity (MFI). All transplants had a negative complement dependent cytotoxicity (CDC) crossmatch prior to transplantation. Flow cytometry crossmatch (FXCM) was performed in selected cases only, performed on peak serum unless otherwise stated. AKX, Australian Kidney Exchange; DTT, dithiothreitol; NP, not performed; Tx, transplant.

\# DSA below cut off for positive test $(>1000)$

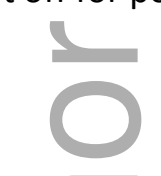

Table 3 Outcomes for Patients Transplanted through the AKX

\begin{tabular}{|c|c|c|c|c|}
\hline Patient & Duration of Follow Up (Months) & eGFR $\left(\mathrm{ml} / \mathrm{min} / 1.73 \mathrm{~m}^{2}\right)$ & \multicolumn{2}{|c|}{ Donor Specific Antibody Testing (MFI) } \\
\hline 1 & 24 & 94 & 12 months & Cw4 (1438) \\
\hline 2 & 26 & 46 & 12 months & A32 (1358); DR 7 (1324); B64 (<1000) \# \\
\hline & & & 18 months & A32 (<1000); DR7 $(<1000)^{\#}$ \\
\hline
\end{tabular}

This article is protected by copyright. All rights reserved 
No DSA

No DSA

eGFR: estimated glomerular filtration rate (calculated using revised Schwartz formula)

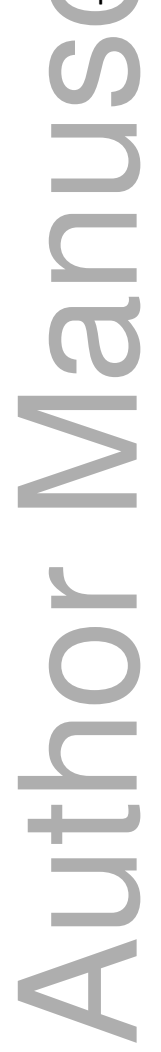

This article is protected by copyright. All rights reserved 


\section{University Library}

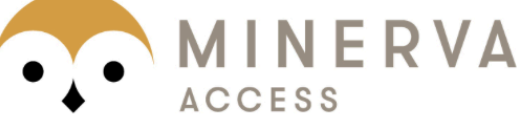

A gateway to Melbourne's research publications

Minerva Access is the Institutional Repository of The University of Melbourne

Author/s:

Sypek, MP;Alexander, SI;Cantwell, L;lerino, FL;Ferrari, P;Walker, AM;Kausman, JY

Title:

Optimizing Outcomes in Pediatric Renal Transplantation Through the Australian Paired Kidney Exchange Program

Date:

2017-02-01

Citation:

Sypek, M. P., Alexander, S. I., Cantwell, L., lerino, F. L., Ferrari, P., Walker, A. M. \& Kausman, J. Y. (2017). Optimizing Outcomes in Pediatric Renal Transplantation Through the Australian Paired Kidney Exchange Program. AMERICAN JOURNAL OF TRANSPLANTATION, 17 (2), pp.534-541. https://doi.org/10.1111/ajt.14041.

Persistent Link:

http://hdl.handle.net/11343/291846

License:

CC BY-NC-ND 